\title{
Daniel Delas (a cura di) Manifestes et magistères
}

\section{Claudia Mansueto}

\section{(2) OpenEdition \\ Journals}

\section{Edizione digitale}

URL: https://journals.openedition.org/studifrancesi/4839

DOI: 10.4000/studifrancesi.4839

ISSN: 2421-5856

\section{Editore}

Rosenberg \& Sellier

\section{Edizione cartacea}

Data di pubblicazione: 1 avril 2012

Paginazione: 193

ISSN: 0039-2944

\section{Notizia bibliografica digitale}

Claudia Mansueto, «Daniel Delas (a cura di) Manifestes et magistères», Studi Francesi [Online], 166 (I LVI) | 2012, online dal 30 novembre 2015, consultato il 19 novembre 2021. URL: http://

journals.openedition.org/studifrancesi/4839; DOI: https://doi.org/10.4000/studifrancesi.4839

Questo documento è stato generato automaticamente il 19 novembre 2021.

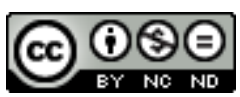

Studi Francesi è distribuita con Licenza Creative Commons Attribuzione - Non commerciale - Non opere derivate 4.0 Internazionale. 


\title{
Daniel Delas (a cura di) Manifestes et magistères
}

\author{
Claudia Mansueto
}

\section{NOTIZIA}

DANIEL DELAS (a cura di) Manifestes et magistères, «Etudes littéraires africaines», 29, 2010, pp. 184.

1 Il dossier contenuto in questo numero di «Études littéraires africaines» è costituito da undici saggi dedicati ai manifesti letterari francofoni che hanno maggiormente sollecitato l'attenzione di critici e scrittori e stimolato la discussione. La volontà che anima l'intero lavoro è quella di analizzare le rivendicazioni letterarie ed identitarie del mondo francofono, espresse attraverso i manifesti. Queste «littératures de l'intraquillité» (p. 8), come vengono definite da Lise GAUviN che parafrasa Pessoa nel saggio Entre rupture et affirmation: les manifestes francophones (pp.7-14), sembrano oscillare tra due poli ideologici opposti: si va infatti dalla filosofia del New Negro del 1925, fondata, come sostiene MANGEON in The New Negro, une Bible de la négritude (pp. 15-19), sul principio di «fierté raciale» (p. 16) - principio recuperato da Senghor, come si evidenzia nel saggio di RANAIVOSON, attraverso il concetto di «unité du monde noir» (p. 25) - fino all'apertura glissantiana verso un orizzonte relazionale dominato, come sottolineano GAUVIN e BREZAULT, da un «mouvement perpétuel d'interpénétrabilité culturelle et linguistique» (p. 12). Glissant invita a «habiter le monde» (p. 43) e la sua aspirazione ha fatto adepti fra molti intellettuali francofoni contemporanei, fra cui, ad esempio, Patrice Nganang che, secondo Viviane AZARIAN in Dissidence et "préemption» dans l'Afrique de Patrice Nganang (pp. 62-68), vuole dare dignità planetaria agli scritti dei dissidenti africani, a quelle opere, cioè, che hanno saputo meglio interpretare «les cris de la ville» (p. 63). Contrariamente a quella di Nganang, la scrittura di Nimrod, come evidenzia Daniel DELAS in Le manifeste aristocratique de Nimrod (pp.69-73), è venata di nostalgie "arcaiche". Per lui, lo scrittore è «un prince exilé» (p. 69), il portavoce di un 
mondo che non tornerà più, un solitario chiuso nella sua «tour d'ivoire» (p. 73). Agli antipodi della filosofia di Nimrod, si posiziona quella di Célestin Monga che, come sottolinea Sarah BURNAUTZI in Repenser la négritude: le nihilisme dans le «monde noir» selon Célestin Monga (pp.74-80), tenta di decifrare, e di rendere leggibile per il lettore occidentale, il caos che caratterizza, a suo parere, il mondo africano contemporaneo.

2 Ad arricchire e concludere il "dossier" sui manifesti contribuisce la pubblicazione de Le Manifeste anti- bruit di Lionel MANGA che, contro il proliferare cacofonico della parola, afferma il valore salvifico del silenzio, indispensabile per non soggiacere alla «pression permanente» (p. 86) e fuorviante esercitata dagli stereotipi e dalle convenzioni. Fuggire il contingente, «orbiter loin des lieux communs» (p. 86) garantisce il benessere permettendo di liberare l'uomo dai suoi schemi mentali più usurati. Concludono il numero tre sezioni: Varia (pp. 87-108), dedicata alla poesia di Kapajika Kamundimba; A propos du cinquantenaire: chroniques d'une indepéndance ambiguë (pp. 109-121) ed infine Comptes-rendus, in cui vengono presentate le novità letterarie più interessanti (pp. 123-184). 